\title{
Arterial Carboxyhemoglobin Levels In COVID-19 Critically III Patients
}

\section{Paul Paccaud}

Cliniques Universitaires Saint-Luc

\section{Diego Castanares-Zapatero}

Cliniques Universitaires Saint-Luc

\section{Ludovic Gerard}

Cliniques Universitaires Saint-Luc

\section{Virginie Montiel}

Cliniques Universitaires Saint-Luc

\section{Xavier Wittebole}

Cliniques Universitaires Saint-Luc

\section{Christine Collienne}

Cliniques Universitaires Saint-Luc

\section{Pierre-François Laterre}

Cliniques Universitaires Saint-Luc

Philippe Hantson ( $\nabla$ philippe.hantson@uclouvain.be )

Cliniques Universitaires Saint-Luc https://orcid.org/0000-0003-4409-3352

\section{Research}

Keywords: COVID-19, acute respiratory distress syndrome, inflammation, arterial carboxyhemoglobin, prognosis

Posted Date: November 29th, 2021

DOI: https://doi.org/10.21203/rs.3.rs-68522/v2

License: (c) (i) This work is licensed under a Creative Commons Attribution 4.0 International License. Read Full License 


\section{Abstract}

Objective : Oxidative stress conditions may be responsible for an up-regulation of the expression of heme oxygenase ( $\mathrm{HO})$, the enzyme synthesizing carbon monoxide (CO) in cells. Elevated levels of arterial carboxyhemoglogin $(\mathrm{aCOHb})$ have been found in critically ill patients, including those suffering from acute lung injury. We aimed to investigate the changes of aCOHb levels in COVID-19 critically ill patients.

Design : Single center retrospective cohort study between March 1 and December 31, 2020.

Setting: University teaching hospital with 900 beds including 48 ICU beds.

Patients: Consecutive adults requiring ICU admission for severe COVID-19 infection.

Measurements and main results : After exclusion of 23 patients who required extracorporeal membranous oxygenation (ECMO), a total of 135 patients was considered, from whom 76 required mechanical ventilation (MV) that was prolonged for more than 20 days in 28 patients. Demographics, laboratory values, treatment and outcomes were recorded. The evolution of aCOHb over time was investigated among survivors and non-survivors and among patients with or without MV. The admission and peak $\mathrm{aCOHb}$ values did not differ among survivors or non-survivors. In the patients with $\mathrm{MV}$, there was a significant increase of $\mathrm{aCOHb}$ with time, with a biphasic evolution for the patients ventilated for more than 20 days: a parallel increase of $\mathrm{aCOHb}$ and $\mathrm{PaCO}_{2}$ followed by a trend to a plateau of aCOHb during $\mathrm{PaCO}_{2}$ recovery.

Conclusions: Progressive increase in aCOHb from endogenous source is observed in COVID-19 patients requiring prolonged mechanical ventilation. Decrease of aCOHb appears slower than $\mathrm{PaCO}_{2}$ recovery.

\section{Background}

Elevated carbon monoxide (CO) concentration has been found in exhaled breath of patients suffering from various pulmonary inflammatory disorders. In hemodynamically stable non-smoking patients with no recent exogenous $\mathrm{CO}$ exposure, and provided that ventilatory conditions remain constant, expired $\mathrm{CO}$ reflects endogenous $\mathrm{CO}$ production. Carbon monoxide is mainly derived from heme catabolism, with heme oxygenase being the step-limiting enzyme of the heme degradation. Heme oxygenase exists under three isoforms, one inducible (HO-1) and two constitutives (HO-2 and HO-3). $\mathrm{HO}-1$ isoform is induced within cells mainly during oxidative stress [1]. In the absence of exogenous source of $\mathrm{CO}$, arterial carboxyhemoglobin $(\mathrm{aCOHb})$ reflects the level of endogenous $\mathrm{CO}$ in the lower lungs. We aimed to investigate $\mathrm{aCOHb}$ profiles over time in patients admitted in an intensive care unit (ICU) for severe COVID19 infection, and their relationship with outcome.

\section{Material \& Methods}


This retrospective observational cohort study was performed in a single center, university hospital (900 beds) with a 48 ICU-beds facility. Inclusion criteria were patients older than 18 years admitted to the ICU for COVID-19 infection over the period ranging from March 1, 2020 to December 31, 2020. The trial was conducted with the guiding principles of the Declaration of Helsinki and local ethics committee (Cliniques Universitaires Saint Luc - Université Catholique de Louvain) reviewed the study and waived the need for approval.

The diagnosis of COVID-19 infection was made by the combination of RT-PCR analysis of a nasopharyngeal swab and lung computed tomography (CT). Specific treatment for COVID-19 varied according to the update of international recommendations but all received supplemental oxygen in some form. For the patients who underwent invasive mechanical ventilation $(n=76)$, a lung protective strategy was applied. Ventilator settings including inspired fraction of oxygen $\left(\mathrm{FiO}_{2}\right)$ were adjusted according to the results of arterial blood gas analysis. Patients were ventilated alternating prone with supine position when $\mathrm{PaO}_{2} / \mathrm{FiO}_{2}$ ratio were $<150 \mathrm{mmHg}$. In addition to oxygen, inhaled nitric oxide (iNO) therapy was routinely applied in the presence of refractory hypoxemia or severe pulmonary hypertension. Venovenous extracorporeal membranous oxygenation (VV-ECMO) was used as a rescue therapy in selected cases of refractory hypoxemia or severe respiratory acidosis. Patients who were managed with VV-ECMO were excluded of the analysis, to avoid the interference of intravenous hemolysis induced by ECMO on aCOHb levels.

\section{Data collection}

Clinical data were retrospectively retrieved from Electronic Medical Recording (Qcare PDMS, HIM Health Information Management GmBH, Bad Homberg, Deutschland and EPIC HER, EPIC Systems Corporation, Verona, Wisconsin, USA). Demographic data, underlying conditions, vital signs, laboratory investigations, pharmacological treatment, ventilator settings, adjuvant therapies, were recorded. Acute Physiology and Chronic Health Evaluation II (APACHE II) score and Sequential Organ Failure Assessment (SOFA) score were based on the worst variables recorded in the 24 hours following ICU admission. Patients were followed up until hospital discharge, and outcome was recorded at 28 days and ICU discharge.

\section{Laboratory investigations}

For each patient, the determination of $\mathrm{aCOHb}$ was performed at least four times per day simultaneously to arterial blood gas analysis including PaCO2 measurement by a co-oximeter Radiometer ABL800 (Copenhagen, Denmark) using arterial samples collected from the radial arterial line. Calibration was performed every day. A mean daily value of $\mathrm{aCOHb}$ was recorded for each patient. Venous $\mathrm{COHb}$ was determined once a day, between 04:00 and 06:00 hour a.m., from a sample drawn from the central venous catheter usually inserted in the right jugular vein. This value was subtracted from the aCOHb level measured closest to the same time to calculate the daily arteriovenous difference [a-v] in percent $\mathrm{COHb}$. Serum bilirubin and C-reactive protein (CRP) levels were measured routinely at the hospital laboratory on a daily basis. 
Values were expressed as median (first-third quartiles) or mean (SD) for continuous values and counts (per percent of group) for qualitative variables. The data were subjected to Kolmogorov-Smirnov normality test and Bartlett's test for homogeneity of variance. We compared outcome and demographic variables, sedation and adverse events between subjects groups using the chi-square test (or Fisher exact test when appropriate) and unpaired t test (or the Mann-Whitney test according to statistical distribution) for quantitative data, respectively. Time trends were compared between groups using generalized linear mixed models with the group (survivor or non-survivor and invasive mechanical ventilation vs non invasive mechanical ventilation) as a fixed factor and time as a random repeated factor. To compare time trends of $\mathrm{aCOHb}$ and $\mathrm{PaCO} 2$, values were normalized and the profiles were separated into three distinct periods based on the trends observed, connected at "knot values" (day 20 and day 40), using piecewise linear regression. For each period, estimated regression lines (and their IC95) were calculated, and likelihood ratio test for paired difference between slopes were performed. The null hypothesis was rejected at $p$-values $<0.05$. Analyses were performed using SPSS software, version 25 (IBM, Chicago, IL, USA) and graphed with GraphPad Prism 8.0 (GraphPad Software, La Jolla, CA, USA).

\section{Results}

As summarized in Figure 1, 158 patients were admitted in the ICU for COVID-19 infection from March 1 to December 31, 2020. Among them, 23 underwent VV-ECMO and were excluded from the analysis; 135 patients were included in the final analysis. Demographics, laboratory values, adjuvant treatment and outcomes of the population are detailed in Table I. Smokers represented a smaller than expected percentage of the patients $(n=5,4 \%)$ and all of them had quitted tobacco smoking since several days, due to the duration of the symptoms before ICU admission. 80 patients (59\%) were alive at ICU discharge. Survivors were significantly younger (58 vs 68 years, $p<0.0001$ ), were less likely to have chronic kidney disease, hypertension, or diabetes. Severity scores (SOFA and APACHE II) were significantly lower and $\mathrm{PaO}_{2} / \mathrm{FiO}_{2}$ ratio was significantly higher among survivors than non-survivors. aCOHb upon ICU admission and peak aCOHb did not differ between survivors and non-survivors. As shown in Figure 2, there was a significant increase in $\mathrm{aCOHb}$ with time, up to day 40 , with a subsequent plateau (A). Whereas aCOHb profiles did not differ between survivors and non survivors $(B ; p=0.10)$, patients undergoing invasive mechanical ventilation experienced a significant increase in aCOHb over time from day 0 to day 20, compared with patients who were not under invasive MV ( $; p=0.039)$. No comparison was possible beyond day 20, due to the shorter length of ICU stay of patients without invasive MV.

We investigated whether the duration of mechanical ventilation was associated with the time course of $\mathrm{aCOHb}$. In our cohort, 76 patients underwent invasive mechanical ventilation and, among them, 28 patients underwent "prolonged" (>20 days) mechanical ventilation. Table II compares demographics, adjuvant treatments and outcomes between patients who underwent prolonged MV and patients with shorter duration of MV. There was no difference between groups regarding demographics or baseline characteristics including severity scores. Whereas aCOHb at ICU admission did not differ between groups, 
peak $\mathrm{aCOHb}$ was significantly higher in patients who underwent prolonged mechanical ventilation (3.1 vs $1.8 \%, \mathrm{p}<0.0001$ ). As shown in Figure $3, \mathrm{aCOHb}$ profiles did not differ between survivors and non survivors, among patients who underwent prolonged MV (A), as well as among patients with shorter duration of MV (B).

To explain the correlation between invasive mechanical ventilation and $\mathrm{aCOHb}$ increase over time, we investigated whether aCOHb was correlated with $\mathrm{PaO}_{2} / \mathrm{FiO}_{2}$ ratio or with $\mathrm{PaCO}_{2}$ as surrogates for the severity of pulmonary lesions. With the whole dataset, there was a correlation between $\mathrm{PaCO}_{2}$ and $\mathrm{aCOHb}$ in survivors and non-survivors $\left(\mathrm{R}^{2}=0.33, \mathrm{p}<0.0001\right.$; Figure $\left.4, \mathrm{~A}\right)$. However, the analysis of the profile of $\mathrm{aCoHb}$ and $\mathrm{PaCO}_{2}$ (expressed in standard deviations) performed on a subgroup of patients who underwent extremely prolonged mechanical ventilation ( $>40$ days, $n=14$ ) revealed that the correlation between $\mathrm{aCOHb}$ and $\mathrm{PaCO}_{2}$ varies over time (figure 4, $\mathrm{B}$ ). Indeed, during the first 20 days, there was a parallel increase between aCOHb (daily increase of $11.7 \pm 5.2 \%, 95 \% \mathrm{Cl}$ slope $:+8.9 \% ;+15.0 \%$, $p<0.001$ ) and $\mathrm{paCO}_{2}$ (daily increase of $11.2 \pm 2.2 \%, 95 \% \mathrm{Cl}$ slope $:+10.4 \% ;+13.0 \%, p<0.001$ ) with a nonsignificant likelihood ratio test for paired difference between slopes $(p=0.85)$. However, in the following period of 20 days (day 21 - day 40), an increase in aCOHb was still observed (daily increase of $4 \pm 4.8 \%, 95 \% \mathrm{Cl}$ slope : $+1.2 \% ;+6.7 \%, \mathrm{p}=0.008$ ) whereas there was no increase in $\mathrm{PaCO}_{2}$ (daily increase of $0.4 \pm 2.4 \%, 95 \% \mathrm{Cl}$ slope : $-1.0 \% ;+1.8 \%, \mathrm{p}=0.59$ ), with a significant likelihood ratio test for paired difference between slopes $(p=0.005)$. The same trend was observed for the last period of 20 days, but the low number of patients precluded relevant statistical comparison. A representative example of late discordance between $\mathrm{PaCO}_{2}$ and $\mathrm{aCOHb}$ profiles from a patient with extremely prolonged $\mathrm{MV}$ is shown in supplementary material (supplemental figure 1). Besides, there was no clinically relevant correlation between $\mathrm{PaO}_{2} / \mathrm{FiO}_{2}$ ratio and $\mathrm{aCOHb}$, nor between bilirubin and $\mathrm{aCOHb}$ (not shown). Finally, lower values of $\mathrm{COHb}$ were systematically observed in the venous compartment in comparison with $\mathrm{aCOHb}$, including in the patients with prolonged mechanical ventilation.

\section{Discussion}

Previous investigations have shown that $\mathrm{aCOHb}$ levels may be elevated in trauma and surgical patients $[2,3]$, and in patients with inflammatory lung disease $[4,5]$ and critical illness $[6,7,8]$. The presence and role of $\mathrm{COHb}$ is still debated in COVID-19 patients [9]. The majority of ICU hospitalized COVID-19 patients experienced ARDS, vascular inflammation, thrombosis, and ultimately multi-organ damage. The triggering factors are likely multiple. Among them, excess of free heme is a potential offending agent as it has been shown to exacerbate and contribute to the pathogenesis of numerous inflammatory diseases [10]. Therefore, it may be postulated that accumulated free heme and hemoglobin could be involved in the mechanisms increasing pulmonary permeability and inflammation in COVID-19 patients [11]. Protective mechanisms against free heme include the heme oxygenases, which break down heme into equimolar parts of biliverdin/bilirubin, $\mathrm{CO}$, and iron/ferritin. Neither admission nor peak aCOHb levels were predictive of outcome. The increase in $\mathrm{aCOHb}$ occurred with some delay and was significantly greater in the patients who were mechanically ventilated. Regarding the interpretation of [a-v] $\mathrm{COHb}$, we 
noted this did not change over time and was similar among survivors and non-survivors. On the pooled data for $[a-v] \mathrm{COHb}$, we found lower values (mean $0.2 \%$ ) than those documented in a series of patients with inflammatory diseases who were tested while breathing air room (mean $0.5 \%$ [a-v] $\mathrm{COHb}$ ) [12]. This later series had suggested that the measurement of [a-v] $\mathrm{COHb}$ concentration differences could be a valuable marker to define the site of inflammation as this difference was more pronounced in patients with inflammatory pulmonary diseases in comparison with extrapulmonary inflammatory diseases [12].

The percentage of smokers was low in the present study but consistent with other COVID-19 studies. There was no difference at baseline following ICU admission in $\mathrm{aCOHb}$ levels among smokers and nonsmokers. Therefore, it was assumed that exogenous $\mathrm{CO}$ did not play a significant role. It is also documented that $\mathrm{aCOHb}$ may vary following hemorrhage or hemolysis but these conditions were not encountered in our patients.

The main source of endogenous $\mathrm{CO}$ results from the metabolism of heme by heme oxygenase. There is a direct relationship between the $\mathrm{aCOHb}$ and the endogenous production of $\mathrm{CO}$ either in healthy volunteers or in clinical studies $[6,13,14]$. Changes in ventilator variables may also affect aCOHb concentration [15]. Several factors may affect the elimination of the endogenously produced $\mathrm{CO}$ : CO lung diffusing capacity, alveolar ventilation, lung capillary oxygen pressure, $\mathrm{aCOHb}$ concentration, endogenous $\mathrm{CO}$ production and $\mathrm{CO}$ catabolism. The increase of the inspired fraction of oxygen will logically result in a transient increase in $\mathrm{CO}$ lung elimination as a result of a competition of $\mathrm{CO}$ and $\mathrm{O}_{2}$ for the same binding sites. In addition, an experiment conducted on healthy volunteers showed that inhalation of $\mathrm{FiO}_{2} 1.0$ increase endogenous exhaled levels by a factor of four [16]. In this experiment, the most likely mechanism was $\mathrm{CO}$ displacement from hemoglobin, according to the very short duration of exposure to $\mathrm{FiO}_{2}$ 1.0. This could be different in a setting a prolonged exposure to $\mathrm{FiO}_{2} 1.0$ following hypoxic conditions, with a possible over-expression of HO-1.

In the present study, changes in inspired oxygen fraction or ventilator settings occurred in almost all of the patients, particularly at the acute initial stage. As aCOHb was a mean of 4 to 8 daily values for each patient, we can estimate that these changes would have a minimal impact on CO lung excretion. On the other hand, $\mathrm{aCOHb}$ represents a balance between endogenous $\mathrm{CO}$ production and $\mathrm{CO}$ elimination from blood to lungs and extravascular tissues. It remains difficult to establish if the increase in $\mathrm{aCOHb}$ has to be ascribed to an increase of $\mathrm{CO}$ production or to an impaired $\mathrm{CO}$ elimination through the alveolocapillary membrane. On the whole dataset, there was a correlation between $\mathrm{aCOHb}$ and $\mathrm{PaCO}_{2}$ in both survivors and non-survivors, but a strict parallelism between $\mathrm{CO}$ and $\mathrm{CO}_{2}$ pulmonary elimination is not expected. The present study confirms that the respective kinetic profile of $\mathrm{aCOHb}$ and $\mathrm{PaCO}_{2}$ varied over time, with a parallel increase in both $\mathrm{aCOHb}$ and $\mathrm{PaCO}_{2}$ for the patients who were mechanically ventilated $<20$ days, and a discordant evolution over the subsequent period. This was particularly evident for some patients with a very long period of mechanical ventilation and in whom recovery of $\mathrm{PaCO}_{2}$ occurred while high aCOHb values were maintained for a longer period. The reasons for this discrepancy are not precisely known. Release of $\mathrm{COHb}$ from peripheral tissues to venous blood was not documented by 
$\mathrm{vCOHb}$. Difference in diffusion capacity between $\mathrm{CO}$ and $\mathrm{CO}_{2}$ appears unlikely. A third hypothesis should be that induction of heme catabolism mediated by HO-1 could be prolonged following a sustained hypoxic or inflammatory stress.

Indeed, the heme-catabolizing enzyme heme oxygenase ( $\mathrm{HO})-1$ is highly inducible in oxidative stress. Patients with acute respiratory distress syndrome are reported to have an increased expression of $(\mathrm{HO})-1$ [17]. Arterial carboxyhemoglobin level was measured in a cohort of 1267 ICU patients mainly admitted after cardiovascular surgery. Both low minimum and high maximum levels of aCOHb were associated with increased intensive care mortality [18]. Arterial carboxyhemoglobin levels also correlated with biomarkers of the inflammatory response. These data suggested that the failure to up-regulate the activity of the $\mathrm{HO}$ system in the presence of a pro-inflammatory stress may be associated with a worse prognosis, while excessive (HO)-1 induction may also affect negatively the outcome. In patients from a medical ICU, survivors had slightly higher minimal and marginally higher average aCOHb levels when compared to non-survivors [19].

The administration of exogenous $\mathrm{CO}$ has been proposed as therapeutic intervention in various conditions including acute lung injury [20-22]. Contrasting results have been published as some in vivo studies suggested that the endogenous production of $\mathrm{CO}$ or its exogenous administration was protective, while other studies were negative [23]. In a human model of sepsis-related ARDS, inhalation of low doses of CO was associated with an increase in $\mathrm{aCOHb}$ ranging from 3.48 to $4.9 \%$. No serious adverse events occurred in the CO-treated group, while circulating mitochondrial DNA levels were reduced [24].

Carbon monoxide can confer anti-inflammatory protection in rodent models of ventilator-induced lung injury (VILI). This modulation could be partly due to an increased expression of caveolin-1 [21]. Among the drugs recently proposed to treat COVID-19 infection, the effect of dexamethasone remains debatable as it may induce HO-1 in macrophages in some experimental conditions [25]. Induction of HO-1 can also been achieved by a large variety of agents, including aspirin, statins, probucol, valsartan, niacin, resveratrol, and curcumin. The possible role of inhaled nitric oxide (iNO) therapy on carboxyhemoglobin formation is poorly documented in humans $[26,27]$. While NO has been reported to induce HO-1 expression in various cell types, iNO is usually considered has having minimal systemic dissemination [28]. In the present series, the patients who received iNO therapy should not be excluded from the analysis as it may be assumed that iNO therapy was applied to the most severe patients who were more prone to develop high aCOHb levels.

\section{Conclusions}

In conclusion, COVID-19 patients who required prolonged mechanical ventilation ( $>20$ days) had a parallel increase of both $\mathrm{PaCO}_{2}$ and $\mathrm{aCOHb}$ over the first 20 days, with a discordant evolution over the following period. The slower recovery of $\mathrm{aCOHb}$ should reflect prolonged heme catabolism in a chronic hypoxic or inflammatory setting. 


\section{Declarations}

Ethics approval and consent to participate. The trial was conducted with the guiding principles of the Declaration of Helsinki and local ethics committee (Cliniques Universitaires Saint Luc - Université Catholique de Louvain) reviewed the study and waived the need for approval.

Consent for publication. Not applicable.

Availability of data and materials. The datasets used and/or analysed during the current study are available from the corresponding author on reasonable request.

Competing interests. The authors declare that they have no competing interests.

Funding. No sources of funding.

Authors' contributions. AL and PP collected the data, DG performed the statistical analysis, LG analyzed the data and reviewed statistical data, $\mathrm{PH}$ drafted the retrospective study and the first version of the manuscript, CC, XW, JBM, VM, PFL were directly involved in the patients' management and revised the draft version. All authors read and approved the final manuscript.

\section{References}

1. Appegate LA, Luscher P, Tyrell RM. Induction of heme oxygenase : a general response to oxidant stress in cultured mammalian cells. Cancer Res 1991;51:974-978.

2. Moncure M, Brathwaite CE, Samaha E, Marburger R, Ross SE. Carboxyhemoglobin elevation in trauma victims. J Trauma 1999;46:424-427.

3. Sakamoto A, Nakanishi K, Takeda S, Ogawa R. Does carboxy-hemoglobin serve as a stress-induced inflammatory marker reflecting surgical insults? J Nippon Med Sch 2005;72:19-28.

4. Yasuda H, Yamaya M, Yanai M, Ohrui T, Sasaki H. Increased blood carboxyhaemoglobin concentrations in inflammatory pulmonary diseases. Thorax 2002;57:779-783.

5. Yasuda H, Yamaya M, Nakayama K, Ebihara S, Sasaki T, Okinaga S, et al. Increased arterial carboxyhemoglobin concentrations in chronic obstructive pulmonary disease. Am J Respir Crit Care Med 2005;171:1246-1251.

6. Morimatsu H, Takahashi T, Maeshima K, Inoue K, Kawakami T, Shimizu H, t al. Increased heme catabolism in critically ill patients: correlation among exhaled carbon monoxide, arterial carboxyhemoglobin, and serum bilirubin IXalpha concentrations. Am J Physiol Lung Cell Mol Physiol 2006;290:L114-L119.

7. Hunter K, Mascia M, Eudaric P, Simpkins $C$. Evidence that carbon monoxide is a mediator of critical illness. Cell Mol Biol (Noisy-le-grand). 1994;40:507-510.

8. Shi Y, Pan F, Li H, Pan J, Qin S, Jiang D, et al. Carbon monoxide concentrations in paediatric sepsis syndrome. Arch Dis Child 2003;88:889-890. 
9. Scholkmann F, Restin T, Ferrari M, Quaresima V. The Role of Methemoglobin and Carboxyhemoglobin in COVID-19: A Review. J Clin Med. 2020;10:50.

10. Wagener FADTG, Pickkers P, Peterson SJ, Immenschuh S, Abraham NG. Targeting the Heme-Heme Oxygenase System to Prevent Severe Complications Following COVID-19 Infections. Antioxidants (Basel) 2020;9:540.

11. Meegan JE, Shaver CM, Putz ND, Jesse JJ, Landstreet SR, Lee HNR, et al. Cell-free hemoglobin increases inflammation, lung apoptosis, and microvascular permeability in murine polymicrobial sepsis. PLoS One 2020;15:e0228727.

12. Yasuda H, Sasaki T, Yamaya M, Ebihara S, Maruyama M, Kanda A, et al. Increased arteriovenous carboxyhemoglobin differences in patients with inflammatory pulmonary diseases. Chest 2004;125:2160-2168.

13. Wald N, Idle M, Boreham J, Bailey A. Carbon monoxide in breath in relation to smoking and carboxyhaemoglobin levels. Thorax 1981;36:366-369.

14. Coburn RF, Forster RE, Kane PB. Considerations of the physiological variables that determine the blood carboxyhemoglobin concentration in man. J Clin Invest 1965;44:1899-1910.

15. Zegdi R, Caid R, Van de Louw A, Perrin D, Burdin M, Boiteau R, et al. Exhaled carbon monoxide in mechanically ventilated critically ill patients: Influence of inspired oxygen fraction. Intensive Care Med 2000;26:1228-1231.

16. Brenckmann V, Ventrillard I, Romanini D, Jaulin K, Calabrèse P, Briot R. High inhaled oxygen concentration quadruples exhaled $\mathrm{CO}$ in healthy volunteers monitored by a highly sensitive laser spectrometer. Sci Rep 2019;9:12259

17. Mumby S, Upton RL, Chen Y, Stanford SJ, Quinlan GJ, Nicholson AG, et al. Lung heme oxygenase-1 is elevated in acute respiratory distress syndrome. Crit Care Med 2004;32:1130-1135.

18. Melley DD, Finney SJ, Elia A, Lagan AL, Quinlan GJ, Evans TW. Arterial carboxyhemoglobin level and outcome in critically ill patients. Crit Care Med 2007;35:1882-1887.

19. Fazekas AS, Wewalka M, Zauner C, Funk GC. Carboxyhemoglobin levels in medical intensive care patients: a retrospective, observational study. Crit Care 2012;16:R6.

20. Dolinay T, Szilasi M, Liu M, Choi AM. Inhaled carbon monoxide confers antiinflammatory effects against ventilator-induced lung injury. Am J Respir Crit Care Med 2004;170:613-620.

21. Hoetzel A, Schmidt R, Vallbracht S, Goebel U, Dolinay T, Kim HP, et al. Carbon monoxide prevents ventilator-induced lung injury via caveolin-1. Crit Care Med 2009;37:1708-1715.

22. Otterbein LE, Mantell LL, Choi AM. Carbon monoxide provides protection against hyperoxic lung injury. Am J Physiol 1999;276:L688-L694.

23. Clayton CE, Carraway MS, Suliman HB, Thalmann ED, Thalmann KN, Schmechel DE, et al. Inhaled carbon monoxide and hyperoxic lung injury in rats. Am J Physiol Lung Cell Mol Physiol 2001;281:L949-L957. 
24. Fredenburgh LE, Perrella MA, Barragan-Bradford D, Hess DR, Peters E, Welty-Wolf KE, et al. A phase I trial of low-dose inhaled carbon monoxide in sepsis-induced ARDS. JCI Insight 2018;3:e124039.

25. Vallelian F, Schaer CA, Kaempfer T, Gehrig P, Duerst E, Schoedon G, et al. Glucocorticoid treatment skews human monocyte differentiation into a hemoglobin-clearance phenotype with enhanced heme-iron recycling and antioxidant capacity. Blood 2010;116:5347-5356.

26. Ruisi P, Ruisi M. Carboxyhemoglobin formation secondary to nitric oxide therapy in the setting of interstitial lung disease and pulmonary hypertension. South Med J 2011;104:46-8.

27. Rusca M, Oddo M, Schaller M-D, Liaudet L. Carboxyhemoglobin formation as an unexpected side effect of inhaled nitric oxide therapy in severe acute respiratory distress syndrome. Crit Care Med 2004;32:2537-2539.

28. Morse D, Choi AM : Heme oxygenase-1 : The « emerging molecule » has arrived. Am J Respir Cell Mol Biol 2002;27:8-16.

\section{Tables}

Table I. Demographics, baseline characteristics, adjuvant treatment and outcomes of the whole study population (survivors, non-survivors) 


\begin{tabular}{|c|c|c|c|c|}
\hline Variables & $\begin{array}{l}\text { All subjects } \\
(\mathrm{n}=135)\end{array}$ & $\begin{array}{c}\text { Survivors } \\
(\mathrm{n}=80)\end{array}$ & $\begin{array}{l}\text { Non survivors } \\
(\mathrm{n}=55)\end{array}$ & $\mathrm{p}$ \\
\hline Age, median (IQR), years & $64(59-71)$ & $58(54-67)$ & $68(62-76)$ & $\begin{array}{c}< \\
0.0001\end{array}$ \\
\hline Male, n (\%) & $101(75)$ & $63(79)$ & $38(69)$ & 0.23 \\
\hline Body Mass Index $(\mathrm{kg} / \mathrm{m} \square)$, median (IQR) & $\begin{array}{l}28.5(24.5- \\
32)\end{array}$ & $29(24.5-33)$ & $28(24-31)$ & 0.2806 \\
\hline Immunocompromised, n (\%) & $31(23)$ & $18(22,5)$ & $13(24)$ & $\begin{array}{c}> \\
0.9999\end{array}$ \\
\hline Chronic respiratory disease, $\mathrm{n}(\%)$ & $7(5)$ & $3(4)$ & $4(7)$ & 0.4424 \\
\hline Chronic Kidney Disease, n (\%) & $13(9.6)$ & $4(5)$ & $9(16)$ & 0.0377 \\
\hline Hypertension, $\mathrm{n}(\%)$ & $88(65)$ & $46(57.5)$ & $42(76)$ & 0.0280 \\
\hline Diabetes Mellitus, n (\%) & $45(33)$ & $19(24)$ & $26(47)$ & 0.0055 \\
\hline Active smokers, n (\%) & $5(4)$ & $4(5)$ & $1(2)$ & 0.42 \\
\hline APACHE II Score & $15(12-18)$ & $13(10-16)$ & $17(14-21)$ & $<0.0001$ \\
\hline $\begin{array}{l}\text { SOFA Score (ARDS diagnosis day), median } \\
\text { (IQR) }\end{array}$ & $5.3(4-7)$ & $4.7(3-6)$ & $6(4-7)$ & 0.0036 \\
\hline CRP (ICU admission), mg/dl, median (IQR) & $142(80-213)$ & $143(81-207)$ & $142(77-235)$ & 0.99 \\
\hline $\begin{array}{l}\text { Bilirubin (ICU admission), mg/dl, median (IQR) } \\
(\mathrm{n}=81)\end{array}$ & $0.5(0.4-0.8)$ & $0.5(0.4-0.7)$ & $0.55(0.4-0.9)$ & 0.31 \\
\hline Arterial $\mathrm{COHb}$ admission, median (IQR), (\%) & $\begin{array}{l}0.97(0.8- \\
1.1)\end{array}$ & $\begin{array}{l}1.013(0.8- \\
1.1)\end{array}$ & $0.94(0.75-1.1)$ & 0.4081 \\
\hline $\begin{array}{l}\text { Arteriovenous difference } \mathrm{COHb} \text { (ICU stay), } \\
\text { mean (SD) }\end{array}$ & $0.20 \pm 0.35$ & $0.20 \pm 0.25$ & $0.19 \pm 0.46$ & 0.76 \\
\hline Highest arterial COHb (IQR), (\%) & $\begin{array}{l}2.42(1.6- \\
3.17)\end{array}$ & $\begin{array}{l}2.48(1.6- \\
3.4)\end{array}$ & $2.11(1.5-2.73)$ & 0.1126 \\
\hline $\mathrm{PaO} 2 / \mathrm{FiO} 2$ ratio baseline, median (IQR), $\mathrm{mmHg}$ & $89(61-106)$ & $\begin{array}{l}96.5(62- \\
110)\end{array}$ & $78(60-94)$ & 0.0280 \\
\hline Invasive mechanical ventilation, $\mathrm{n}(\%)$ & $76(56)$ & $30(37)$ & $46(84)$ & $<0.0001$ \\
\hline $\begin{array}{l}\text { Mechanical ventilation duration, median(IQR), } \\
\text { days }\end{array}$ & $24(7-36)$ & $34(7-59)$ & $18(7-23)$ & 0.0037 \\
\hline ICU length of stay, median (IQR), days & $21(3-23)$ & $23(2-25)$ & $17(6-23)$ & 0.2495 \\
\hline
\end{tabular}

ARDS: acute respiratory distress syndrome, IQR: interquartile range; SOFA: Sequential Organ Failure Assessment; ICU: Intensive Care Unit

Table II. Demographics, baseline characteristics, adjuvant treatment and outcomes of the 76 patients with severe SARS-CoV2 infection who underwent invasive mechanical ventilation $(<20$ days vs $>20$ days) 


\begin{tabular}{|c|c|c|c|c|}
\hline Variables & $\begin{array}{c}\text { All } \\
\text { patients } \\
(\mathrm{n}=76)\end{array}$ & $\begin{array}{l}\text { Mechanical ventilation }< \\
20 \text { days }(\mathrm{n}=48)\end{array}$ & $\begin{array}{c}\text { Mechanical ventilation }> \\
20 \text { days }(\mathrm{n}=28)\end{array}$ & $\mathrm{p}$ \\
\hline Age, median (IQR), years & $\begin{array}{l}64(57- \\
71)\end{array}$ & $64(57-72)$ & $64(59-69)$ & 0.9431 \\
\hline Male, n (\%) & $54(71)$ & $33(69)$ & $21(75)$ & 0.6103 \\
\hline $\begin{array}{lccc}\text { Body } & \text { Mass } & \text { Index } & (\mathrm{kg} / \mathrm{m} \square) \\
\text { median } & (\mathrm{IQR}) & & \end{array}$ & $\begin{array}{c}28 \\
(24.5- \\
31)\end{array}$ & $27.5(24.5-30)$ & $28.5(25-32)$ & 0.4375 \\
\hline Immunocompromised, $\mathrm{n}(\%)$ & $23(30)$ & $14(29)$ & $9(32)$ & 0.6297 \\
\hline $\begin{array}{l}\text { Chronic respiratory disease, } \mathrm{n} \\
(\%)\end{array}$ & $5(6.5)$ & $1(2)$ & $4(14)$ & 0.0691 \\
\hline $\begin{array}{l}\text { SOFA (ARDS diagnosis day), } \\
\text { median (IQR) }\end{array}$ & $\begin{array}{l}5.9(4- \\
7)\end{array}$ & $5.9(4-8)$ & $5.9(4-7)$ & 0.9756 \\
\hline Chronic Kidney Disease, n (\%) & $\begin{array}{c}11 \\
(14,5)\end{array}$ & $8(17)$ & $3(11)$ & 0.3320 \\
\hline $\begin{array}{lll}\mathrm{PaO} 2 / \mathrm{FiO} 2 & \text { ratio } & \text { baseline, } \\
\text { median }(\mathrm{IQR}), \mathrm{mmHg} & \end{array}$ & $\begin{array}{l}83(57- \\
99)\end{array}$ & $88(57-120)$ & $74.5(58-81)$ & 0.1449 \\
\hline Chronic Hypertension, n (\%) & $60(79)$ & $33(69)$ & $20(71)$ & $>0.9999$ \\
\hline Diabetes Mellitus, n (\%) & $38(50)$ & $20(42)$ & $11(39)$ & 0.1537 \\
\hline Chronic Heart Failure, n (\%) & $\begin{array}{l}39.5 \\
(29)\end{array}$ & $15(31)$ & $11(39)$ & 0.6168 \\
\hline $\begin{array}{l}\text { ICU length of stay, median } \\
\text { (IQR), days }\end{array}$ & $\begin{array}{l}30(8- \\
37)\end{array}$ & $11(6-15.5)$ & $62(36-74)$ & $<0.0001$ \\
\hline $\begin{array}{l}\text { Arterial } \mathrm{COHb} \\
\text { median (IQR), (\%) }\end{array}$ & $\begin{array}{c}0.97 \\
(0.8- \\
1.1)\end{array}$ & $0.96(0.73-1.1)$ & $0.99(0.86-1.1)$ & 0.7381 \\
\hline $\begin{array}{l}\text { Highest arterial } \mathrm{COHb} \text { (IQR), } \\
\text { (\%) }\end{array}$ & $\begin{array}{l}2.3(1.6- \\
3)\end{array}$ & $1.8(1.4-2.3)$ & $3.12(2.6-3.45)$ & $<0.0001$ \\
\hline ICU mortality, n (\%) & $34(45)$ & $18(37,5)$ & $16(57)$ & 0.1508 \\
\hline $\begin{array}{l}\text { Mechanical ventilation duration, } \\
\text { median(IQR), days }\end{array}$ & $\begin{array}{l}24(7- \\
36)\end{array}$ & $9(5-14)$ & $47(24.5-66)$ & $<0.0001$ \\
\hline
\end{tabular}

\section{Figures}




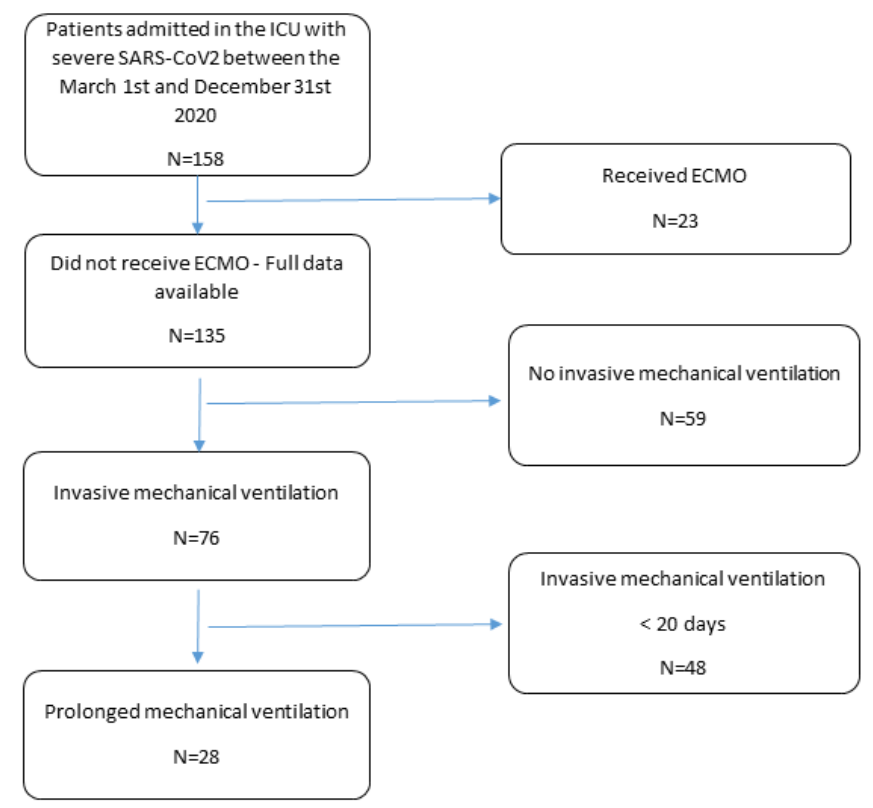

Figure 1

Flow chart of the study population.
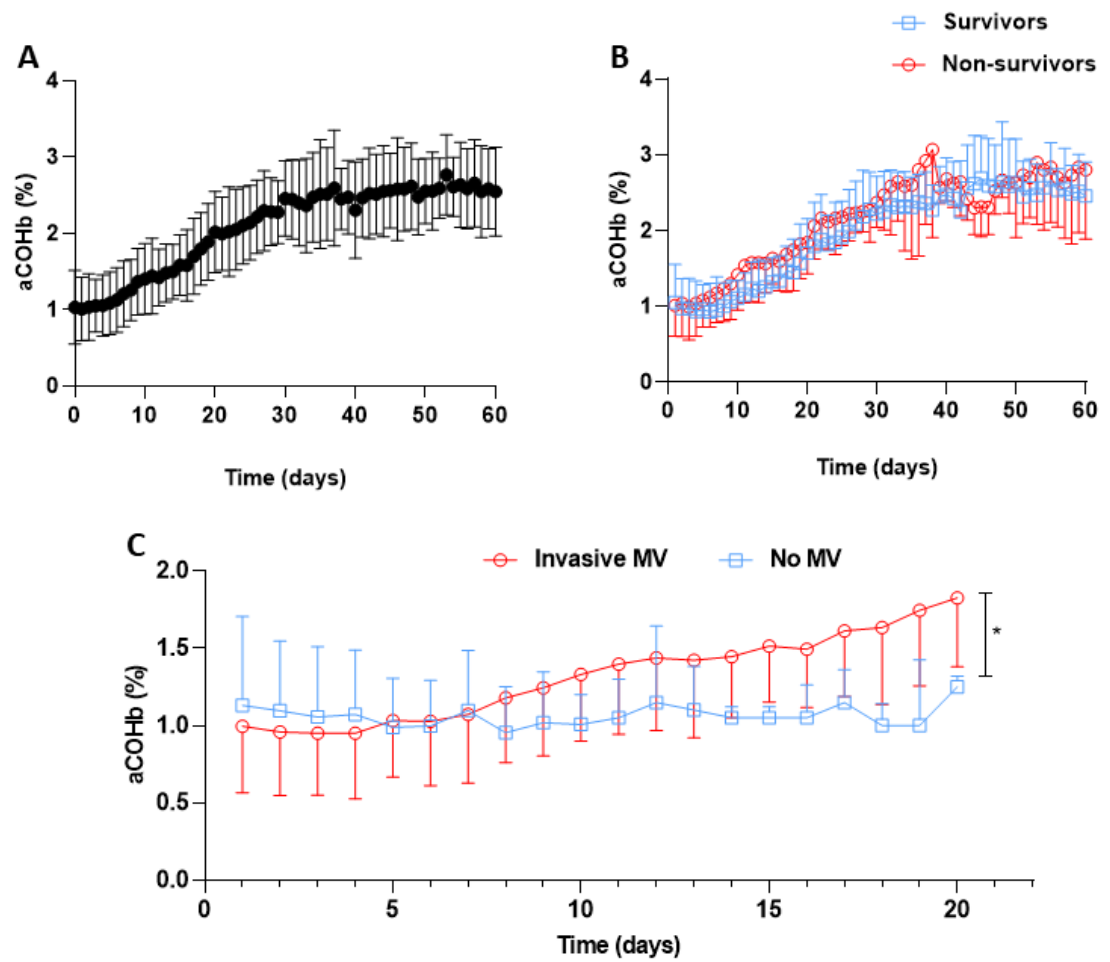


\section{Figure 2}

A. Evolution of $\mathrm{aCOHb}$ from day 0 to day 60 in the whole study population ( $\mathrm{n}=135$ patients). B. Evolution of $\mathrm{aCOHb}$ from day 0 to day 60 comparing 80 survivors with 55 non-survivors. C. Evolution of aCOHb from day 0 to day 20 comparing 76 patients who underwent invasive mechanical ventilation with 59 patients without invasive mechanical ventilation. Data are expressed as mean \pm standard deviation (SD). * represents $p<0.05$ (generalized linear mixed model analysis).
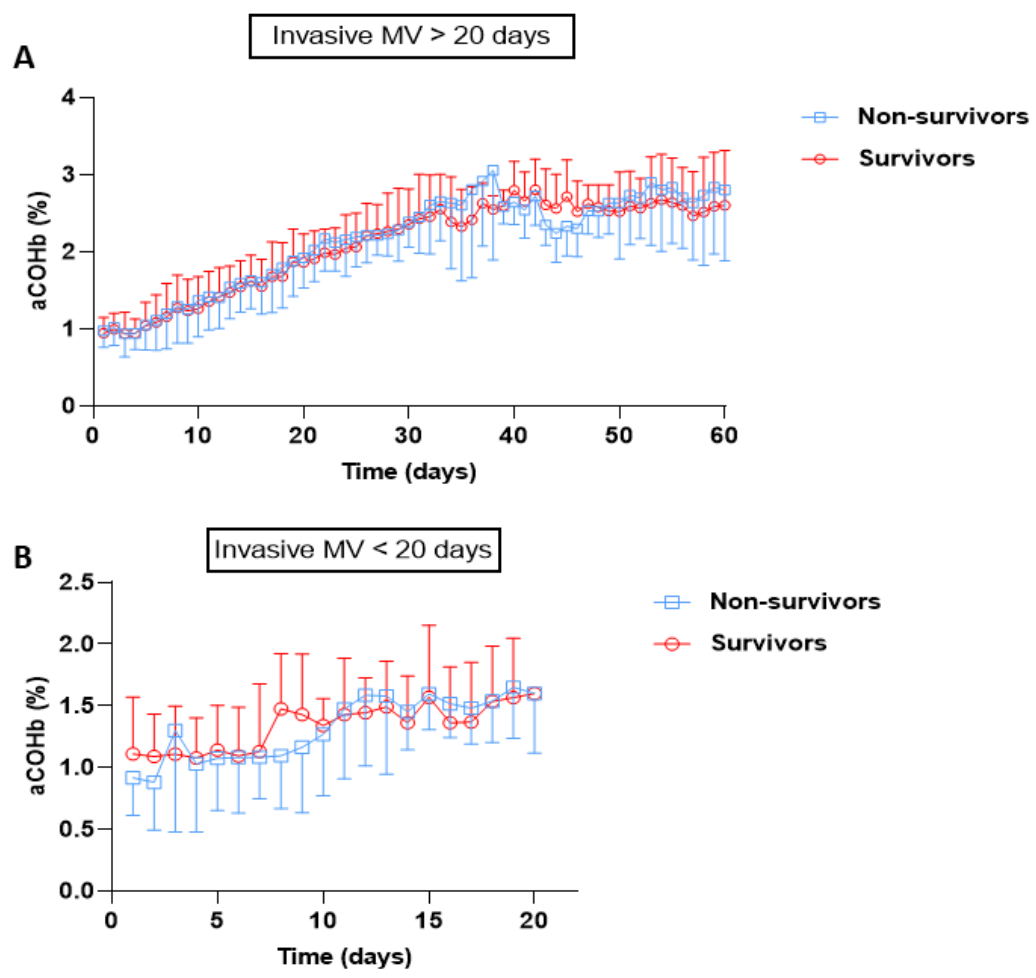

$\square$ Non-survivors

$\ominus$ Survivors

\section{Figure 3}

A. Comparison of the $\mathrm{aCOHb}$ profile from day 0 to day 60 between survivors $(\mathrm{n}=12)$ and non survivors $(n=16)$ among 28 patients who underwent invasive mechanical ventilation $>20$ days. B. Comparison of the $\mathrm{aCOHb}$ profile from day 0 to day 20 between survivors $(n=30)$ and non survivors $(n=18)$ among 48 patients who underwent invasive mechanical ventilation $<20$ days. Data are expressed as mean \pm standard deviation. 

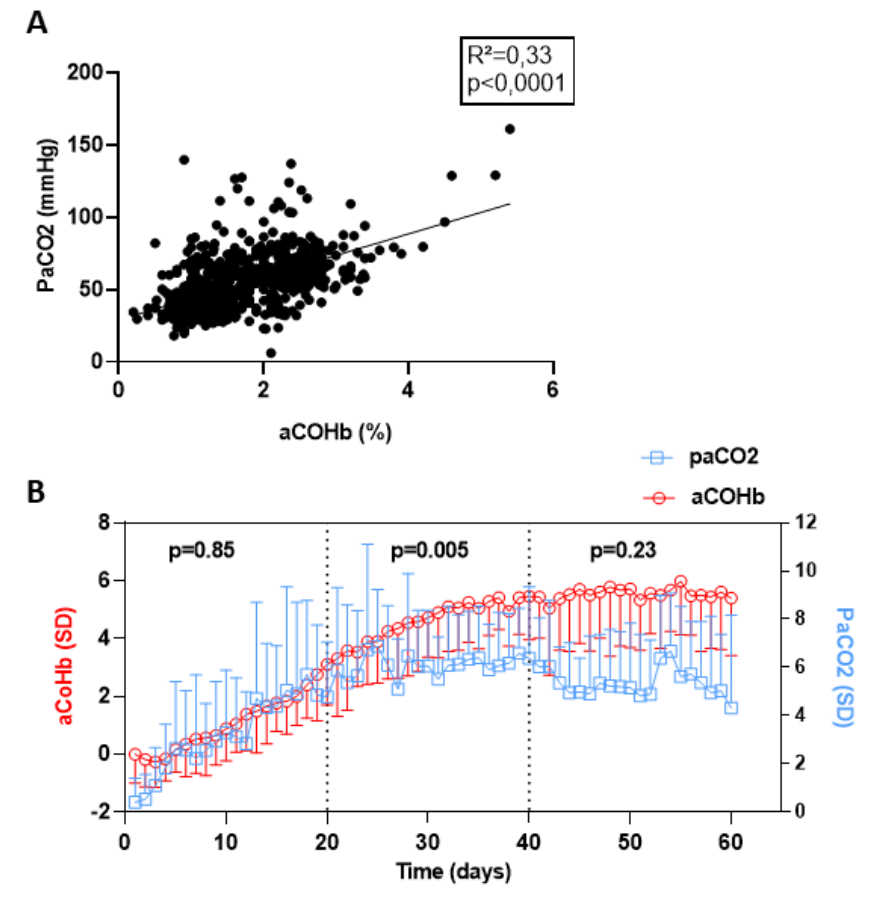

\section{Figure 4}

A. Correlation between aCOHb and PaCO2. B. Comparison of aCOHb (left $\mathrm{Y}$ axis) and $\mathrm{PaCO} 2$ (right $\mathrm{Y}$ axis) profiles (normalized and expressed as standard deviation) from day 0 to day 60 among 14 patients with extremely prolonged mechanical ventilation ( $>40$ days). Likelihood ratios for paired difference between slopes were calculated for the period ranging from day 0 to day 20, from day 21 to day 40 and from day 41 to day 60 .

\section{Supplementary Files}

This is a list of supplementary files associated with this preprint. Click to download.

- SuppIFigureCO.tif 